American Journal of Applied Sciences 5 (10): 1376-1383, 2008

ISSN 1546-9239

(C) 2008 Science Publications

\title{
Spatial-Temporal Yield Trend of Oil Palm as Influenced by Nitrogen Fertilizer Management
}

\author{
${ }^{1}$ Abdul Rahim Anuar, ${ }^{2}$ Kah Joh Goh, ${ }^{2}$ Tee Bee Heoh and ${ }^{3}$ Osumanu Haruna Ahmed \\ ${ }^{1}$ Department of Land Management, Faculty of Agriculture, Universiti Putra Malaysia, \\ 43400 Serdang, Selangor, Malaysia \\ ${ }^{2}$ Applied Agricultural Research Sdn. Bhd., Locked Bag 212, Sungai Buloh Pos Office, \\ 47000 Sungai Buloh, Selangor, Malaysia \\ ${ }^{3}$ Department of Crop Science, Faculty of Agriculture and Food Sciences, Universiti Putra Malaysia \\ Bintulu Campus, 97008 Bintulu, Sarawak, Malaysia
}

\begin{abstract}
One of the major challenges in oil palm (Elaeis guineensis Jacq.) plantations today is proper interpretation of yield maps for site-specific management and identification and understanding of the causal factors influencing the variability of oil palm yields. A study was conducted to examine the structural yield variation in order to assess the spatial and temporal yield trends so as to interpret multiyear yield maps of oil palm as influenced by the long-term $\mathrm{N}$ fertilizer applications in the palm circle in fertilizer response trial in Sabah, Malaysia. Two clusters of palms were selected for the study; with and without $\mathrm{N}$ fertilizer applications for the past 10 years. Fresh fruit bunch (ffb) yields were recorded and summarized on an annual basis. Geostatistical analysis was used to characterize the spatial structure of the semivariogram while point kriging was used to interpolate the ffb yields at unsampled locations. A classified management zone map was developed based on the spatial and temporal stability yield maps from 1992-1999. Semivariance analysis revealed that the yield variations between plots and within plots could be distinguished from the structural semivariogram. The variability between plots was relatively higher compared with within plots. The maximum range of the semivariance of both fertilizer treatments was about 6-palm distance which corresponded well to the experimental plot size of $30(5 \times 6)$ palms. It was also observed that the structure of the semivariogram was governed by the sampling pattern and the experimental plot size. The annual yield maps suggested that the application of $\mathrm{N}$ could sustain ffb yields above $30 \mathrm{t} \mathrm{ha}^{-1}$ year $^{-1}$ whereas its removal could result in a drastic decline in $\mathrm{ffb}$ yields after 1992. Long-term $\mathrm{N}$ fertilizer applications reduced the annual ffb yield fluctuations to between 35 and $45 \%$ based on the coefficient of variations between years obtained from individual palms. The results further demonstrate the potential of integrating spatial and temporal stability of ffb yields from multi-year yield data to classify management zones for site-specific oil palm management particularly for fertilizer application. However, the potential of misinterpretation of yield maps can be high if limited data are available. Further work is necessary to ascertain the minimum number of palms and years required for the generation of meaningful yield maps and management zones.
\end{abstract}

Key words: Spatial variability, nitrogen fertilizer, oil palm yield, Malaysia

\section{INTRODUCTION}

The large variation in the fresh fruit bunch (ffb) yields between individual oil palms has been recognized since their commercial cultivation in the 1920s. The average $\mathrm{ffb}$ yields in Malaysia ranged from 18-20 $\mathrm{t}$ but in efficient commercial estates it can exceed $30 \mathrm{t} \mathrm{ha}^{-1}$ year $^{-1}$. In fact, an average of $30 \mathrm{t} \mathrm{ha}^{-1}$ year $^{-1}$ was reported by Tarmizi et al. ${ }^{[1]}$ and Goh et al. ${ }^{[2]}$ on a wide range of fertilizer response trials. This yield is very much below the theoretical yield potential of $44 \mathrm{t}$ ha $^{-1}$ year $^{-1[3,4]}$.

Apart from the above, uniformity trials with oil palm have generally shown that the coefficient of variations (CV) of ffb yields could exceed 30. ${ }^{[5,6,7]}$. They also vary spatially and temporally ${ }^{[7,8,9]}$, which

Corresponding Author: Osumanu Haruna Ahmed, Department of Land Management, Faculty of Agriculture and Food Sciences, Universiti Putra Malaysia Bintulu Campus, Malaysia, 97008 Bintulu, Sarawak, Malaysia Tel: +6086-855406 
suggest that some palms will consistently produce higher or lower yields than the field average while other palms may produce higher or lower yields in some years but not others.

However, the $\mathrm{CV}$ is non-spatial and does not distinguish between autocorrelated yield variation (which is manageable) and uncorrelated (nugget) variation (which is not manageable ${ }^{[10]}$. Goh et al. ${ }^{[9]}$ used geostatistics to demonstrate that the yield variation of oil palm could be separated into spatial and random components. The spatial variability accounted for $75 \%$ of the total variation in the field, which is manageable if the causal factors can be identified. They further showed that distinct spatial patterns in ffb yields existed in their experimental field of 25 ha. Several portions of the field had consistently higher or lower ffb yields compared with the field average over the past 8 years. They postulated that soil nitrogen and water availability might be the main causes for the variation in ffb yields.

The high variation in ffb yields is probably best represented with yield maps for better visualization. This technique is now commonly used in developed countries to interpret and manage the yield variations of many crops for precision farming ${ }^{[11,12,13]}$. Also, it could be used to classify a large field into different management zones for site specific inputs to optimize productivity and profitability; two of the most important keys towards sustainability of oil palm plantations ${ }^{[14]}$. Management zoning is widely practiced in the oil palm plantations but its spatial scale at 30 to 60 ha is generally too large for site specific management ${ }^{[14]}$. Furthermore, the interpretation of trend from multiple yield maps of the same location and the development of a method to optimize management zoning for precision farming have not been well explored in the oil palm plantations. These will depend on the existence of manageable yield variations and a proper understanding of the yield variations.

Thus, the main objective of this study were to quantify and characterize the spatial and temporal variation of $\mathrm{ffb}$ yields so as to determine the optimum management zones for oil palm plantations, as well as to create possible management zones for site-specific inputs

\section{MATERIALS AND METHODS}

The experiment was located within a fertilizer response trial conducted by Applied Agricultural Research Sdn. Bhd. at Sri Kunak Estate, Tawau, Sabah, Malaysia. The oil palms were planted in 1982 in a triangular pattern with a planting distance of $9.1 \mathrm{~m} \times 9.1$ $\mathrm{m} 9.1 \mathrm{~m}$. The experimental design comprised a $3 \times 3 \times 2$ factorial combination of $\mathrm{N}, \mathrm{P}$ and $\mathrm{K}$ arranged in a randomized complete block design (RCBD) with 3 replicates. The experiment consisted of 18 plots for each replicate with a plot size of 30 palms. Fresh fruit bunch yields were recorded from the 12 central palms at 10 day intervals. An initial assessment of ffb yields in the experimental site indicated that a thin layer of laterites in some of the plots was a major cause of yield variation. Apart from this, variation in soil nitrogen might affect the spatial yield variation of oil palm in the experiment.

Two clusters of palms were therefore selected for the study. The first cluster composed of oil palms that had been fertilized with $\mathrm{N}$ while the other had not been fertilized for the past 10 years. A total of 8 plots were selected, 4 plots with $\mathrm{N}$ and 4 plots without $\mathrm{N}$ respectively. Point map of the individual palms for both treatments, which showed their relative positions in the field, was geocoded using non-earth system in meter unit. The plot size for the $\mathrm{N}$ treatment was 160 $\mathrm{m} \times 90 \mathrm{~m}$ and for non- $\mathrm{N}$ treatment was $120 \mathrm{~m} \times 115 \mathrm{~m}$ as shown in Fig. 1. Each treatment had 48 measurement palms.

Fresh fruit bunch (ffb) yields were summarized on an annual basis. They were then adjusted using the difference method $^{[15]}$ in order to remove both $\mathrm{P}$ and $\mathrm{K}$ effects. The components of variation in $\mathrm{ffb}$ yields after the removal of all known sources of yield variation

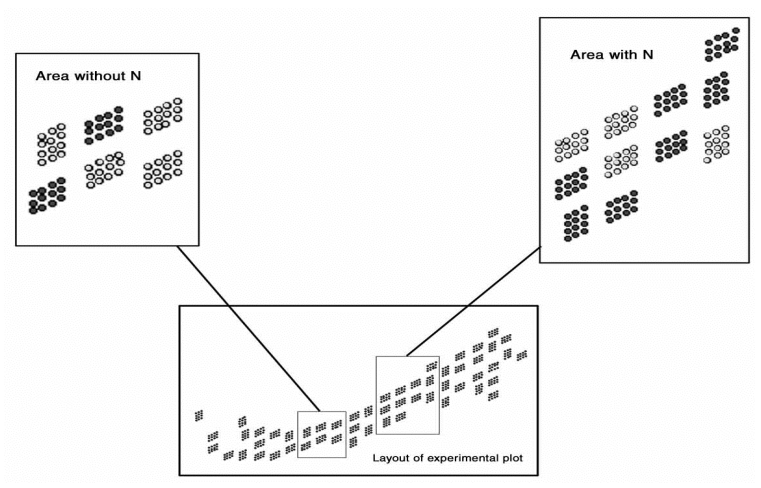

Fig. 1: Diagrammatic representation of experimental site

were calculated using the Statistical Analysis System (SAS) Package ${ }^{[16]}$. The F test was used to ascertain the differences in variations between and within plots.

Geostatistical analysis was performed on the data using semivariogram ${ }^{[17]}$ and kriging $^{[18]}$ analyses. Semivariogram was fitted to the experimental model using Surfer Golden Software, Golden Co. (Demo version 7.0). The active lag distance for the grid in both treatments was limited to a maximum of $100 \mathrm{~m}$. The lag 
Am. J. Applied Sci., 5 (10): 1376-1383, 2008

interval in the semivariogram was fixed at $9.1 \mathrm{~m}$ based on the planting distance of oil palm. Each lag distance class contained at least 60 pairs of points and most had more than 100 pairs of data points. Selection of the models for the semivariogram was made based on Akaike Information Criteria (AIC) following the procedures described by Webster and McBratney ${ }^{[9]}$.

Interpolation of $\mathrm{ffb}$ yields at unsampled area was carried out by kriging using $\mathrm{GS}+{ }^{\mathrm{TM}}$, Gamma Design Software (Version 3.1). The spatial yield maps of ffb were constructed by first using the point kriging method to estimate $\mathrm{ffb}$ yields at unsampled locations and then clustering them into $\mathrm{ffb}$ yield class of $5 \mathrm{t} \mathrm{ha}^{-1}$ year $^{-1}$ at equal contour intervals. To avoid irregular field shape boundary and for comparing among plots with and without $\mathrm{N}$, a rectangular field boundary was selected with extrapolated size of $165 \mathrm{~m}$ wide and $120 \mathrm{~m}$ long. The trend and stability of the yield maps were quantified by working out the corresponding mean and $\mathrm{CV}$ at each point of sampling over the past 8 years (1992-1999) as described by Blackmore ${ }^{[20]}$. Both maps were then combined into a classified management map with 9 different conditions of 3 yield classes and 3 temporal stability.

\section{RESULTS AND DISCUSSION}

Variation in FFB Yields: The ffb yields obtained from plots with and without $\mathrm{N}$ application from 1991 to 1999 are shown in Table 1 . The annual $\mathrm{ffb}$ yields varied with $\mathrm{CV}$ ranging between 30 and $44 \%$ in plots with $\mathrm{N}$ and between 34 and $56 \%$ in plots without $\mathrm{N}$. The high CVs of $\mathrm{ffb}$ yields were consistent with the findings of Webster $^{[5]}$, Chapas ${ }^{[6]}$ (6) and Soh et al. ${ }^{[7]}$ on a wide range of uniformity trials with oil palm. The mean $\mathrm{CV}$ in plot with $\mathrm{N}$ application was lower compared with plot without $\mathrm{N}$, indicating that the applications of $\mathrm{N}$ fertilizer could reduce the yield fluctuation in oil palm. This was in agreement with the work of Lim et al. ${ }^{[21]}$ and Tayeb et $a l^{[22]}$. Goh et $a l^{[2]}$ attributed this phenomenon to the ability of well fertilized oil palms to use their nutrient reserve during the peak physiological yield cycle, which if not replenished quickly leads to a severe decline in yield as observed in unfertilized oil palms.

Table 1: Mean $\left(\mathrm{kg} \mathrm{palm}^{-1}\right)$, coefficient of variation (\%) and range of ffb yields from 1991 to 1999

\begin{tabular}{|c|c|c|c|c|c|c|}
\hline & \multicolumn{3}{|c|}{ Without N } & \multicolumn{3}{|c|}{ With $\mathrm{N}$} \\
\hline & Mean & $\mathrm{CV}$ & Range & Mean & $\mathrm{CV}$ & Range \\
\hline 1991 & 233 & 39.3 & $45-456$ & 239 & 31.3 & $80-393$ \\
\hline 1992 & 169 & 52.4 & $30-464$ & 277 & 34.2 & $87-494$ \\
\hline 1993 & 145 & 55.8 & $0-384$ & 310 & 31.1 & $135-602$ \\
\hline 1994 & 141 & 53.1 & $9-388$ & 308 & 29.3 & $137-546$ \\
\hline 1995 & 138 & 40.5 & $3-256$ & 211 & 31.7 & $37-349$ \\
\hline 1996 & 146 & 37.0 & $41-255$ & 207 & 44.0 & $0-406$ \\
\hline 1997 & 155 & 34.2 & $33-290$ & 232 & 40.3 & $54-471$ \\
\hline 1998 & 112 & 41.8 & $17-244$ & 207 & 37.4 & $36-377$ \\
\hline 1999 & 153 & 38.9 & $0-307$ & 210 & 37.9 & $43-420$ \\
\hline mean & 155 & 43.7 & $20-338$ & 245 & 35.2 & $68-451$ \\
\hline
\end{tabular}

Table 2: Components of yield variation in the trial site, 1992-1999

\begin{tabular}{llll}
\hline Source & DF & Mean Square & F Test \\
\hline Plot & 7 & 35341.75 & $23.66^{*}$ \\
Palm & 11 & 1683.78 & $1.15^{\text {ns }}$ \\
Plot x Palm & 77 & 1466.75 & \\
Total & 95 & & \\
\hline
\end{tabular}

Note: ns denotes not significant at 0.05 probability level; *significant at 0.05 probability level

The average ffb yields over the past 8 years for each palm were used to examine palm to palm variability within the plot. The components of variation obtained from the ANOVA are shown in Table 2. No significant difference was detected between palm within plot although the results showed high coefficients of variation in annual ffb yields of individual palms. Thus, the main source of yield variation was between the plots. Also the classical statistical analysis could not distinguish the types of variability (spatial and random) between the palms within the plot.

Semivariance Analysis: Geostatistical analysis (semivariogram) was used to study the high variation in $\mathrm{ffb}$ yields of individual palms. The semivariograms for both treatments showed strong oscillations with lag distance following the sine wave model. Cressie ${ }^{[23]}$ described this phenomenon as a hole (wave) effect. Further examination of the mean yield in each plot suggested that the sine wave pattern could be attributed to the yield distribution between and within the plots. As the variogram crossed the sampled palms within the plots the variance tended to decrease but it started to increase as it entered the transition zone between the plots. This pattern will repeat itself as it moved within and between the plots. This implies that the variance within plots was relatively smaller compared with the variance between plots as obtained from the classical statistical analysis presented earlier.

An important feature discernible from the semivariogram was the range between the maximum variance which is shown by the amplitude of the wave model. The amplitudes in both treatments generally lied between $25 \mathrm{~m}$ and $80 \mathrm{~m}$, suggesting that the range of the semivariance was within 6-palm distance. This corresponded well to the experimental plot size of 30 palms ( $6 \times 5$ palms), which indicated that the spatial structure of the semivariogram was probably controlled by the sampling pattern and experimental plot size. This concurs with the findings of McBratney and Pringle ${ }^{[24]}$ and show that the variograms and their parameters are functions of sampling interval and the area of the study.

Within the plots, the increase in semivariance generally reached a peak at a lag distance of $25 \mathrm{~m}$. This 
range was equivalent to about 2 to 3 palm distance. This confirms the results obtained by Goh et al. ${ }^{[9]}$ who concluded that although the ability of the oil palm roots to exploit soil resources has been shown to be at least 2 palms away ${ }^{[25,26]}$, the canopy structure of oil palm is such that it affects its immediate neighbors only (overlapping of fronds of oil palm). Thus, the main competition between the oil palms might be for light and immediate soil resources. It might also be construed that the efficiency of oil palm roots to absorb nutrients reduces substantially away from the palm due to limited feeder (tertiary and quaternary) roots ${ }^{[27]}$. This implies that poaching in oil palm is probably up to 3palm distance at the furthest. Hence, trenching might be unnecessary in fertilizer response trials of oil palm if the experimental plots have guard rows of 2 to 3 palms. This result is consistent with the findings of Foster et al. $^{\left[{ }^{[28]}\right.}$ but contradicts those obtained by Ahmad and Chan ${ }^{[29]}$.

The maximum range of 3-palm distance obtained from the semivariance analysis further suggested that with a triangular spacing in oil palm planting pattern, the optimum management zone for oil palm plantations is 37 palms; excluding field road. However, when field roads, which are normally spaced at 20 palm row intervals, are taken into consideration, the minimum size for practical management zone is 140 palms (7 palm rows $\times 20$ palms row $^{-1}$ ), which is approximately 1 hectare. The result is consistent with those obtained by Goh et al. ${ }^{[14]}$.

Spatial Annual Yield Maps of Oil Palm: The spatial yield variation of oil palm was investigated by extrapolating $\mathrm{ffb}$ yield at unsampled locations using point kriging. Although the results from semivariogram analysis showed that the sine wave model was the best function for the $\mathrm{ffb}$ yield data, for practical management purposes, kriging interpolation was performed using the spherical model which was the next best. Observation showed that the removal of fertilizer resulted in a significant drop in ffb yields after 1992. A large proportion of the field without $\mathrm{N}$ had $\mathrm{ffb}$ yields lower than $15 \mathrm{t} \mathrm{ha}^{-1}$ year $^{-1}$ particularly in the northern part. Fresh fruit bunch yields also declined to less than $30 \mathrm{t} \mathrm{ha}^{-1}$ year $^{-1}$ in $\mathrm{N}$ treated plots after 1994. Apart from climatic effect and yield trend, the decline in ffb yields was associated with the severe leaf damage by Darna trima, which was reported in the trial in 1994. Comparing the yield maps of areas with and without $\mathrm{N}$ application indicated that the applications of $\mathrm{N}$ tend to sustain high ffb yields above $30 \mathrm{t} \mathrm{ha}^{-1}$ year $^{-1}$. Nitrogen is probably the major factor affecting the $\mathrm{ffb}$ yield variation of oil palms in the experiment as obtained by Goh et al. ${ }^{[9]}$.

The multi-year yield maps also showed distinct changes in the pattern of ffb yields from the same site. For example, in both treatments, high ffb yields were noted in 1997 followed by low yields in 1998 . Similarly, high yielding area in one year might become low yielding in the next without any changes in the treatments. Such temporal yield variations are common in perennial crops ${ }^{[30]}$ which increase the uncertainty in the interpretation of yield maps for site-specific crop management particularly for the following year(s).

Spatial and temporal stability yield maps of FFB: Blackmore et al. ${ }^{[20]}$ suggested the incorporation of trend and temporal stability of ffb yields into the yield maps to overcome the problems of their interpretation. He divided the field into management zones based on the combination of discrete classifications of mean annual yield and temporal $\mathrm{CV}$ at each sampling point over the years of study. The management zone at each sampled point is then used to produce the management zone map by kriging for future decision making.

Following Blackmore et $a .^{[20]}$, the mean annual ffb yield and temporal $\mathrm{CV}$ of each oil palm were classified into 3 categories of high, moderate and low, each (Table 3). The classification was based on an approximate $1 / 2$ standard deviation of the average $\mathrm{ffb}$ yield of oil palms in the trial site and the acceptable stability of $\mathrm{ffb}$ yields obtained in various uniformity studies as presented earlier. Results indicated that about $99 \%$ of the $\mathrm{N}$ treated palms had yields above $30 \mathrm{t} \mathrm{ha}^{-1}$ year $^{-1}$ whereas only $22 \%$ achieved similar yield in the control palms. The latter was despite the withdrawal of $\mathrm{N}$ fertilizer for 8 years which suggested that the soil $\mathrm{N}$ status and conditions in part of the field were still favourable for high productivity. The control palms also showed a wider spread in the yield classes with the majority falling into the moderate yield category of between 20 and $30 \mathrm{t} \mathrm{ha}^{-1}$ year $^{-1}$.

In terms of temporal stability of ffb yields, the $\mathrm{N}$ treated palms were mainly classified under the stable to fairly stable categories while the converse was true for the control palms (Table 3). About $50 \%$ of the palms in the control plots had unstable ffb yields indicating large fluctuations which might be due to changing endogenous (physiological yield cycle) and exogenous (environmental) factors ${ }^{[31]}$. The results also showed that application of $\mathrm{N}$ tended to sustain high $\mathrm{ffb}$ yields and improve temporal stability of ffb yields; both highly favourable to the management of oil palm ${ }^{[32]}$. However, no spatial information was obtained from the yield 
distribution classes as shown in the Table 3 and spatial analysis was required to ascertain them.

The yield class for each palm was used to produce the yield class map by kriging in order to illustrate its distribution as influenced by $\mathrm{N}$ applications (Fig. 2). As expected, the results for $\mathrm{N}$ treated palms showed a uniform distribution of high yield over the trial site. However, in the area without $\mathrm{N}$ application, low yield was observed in the northern part, stretching from east to west. Although it was tempting to separate the two areas for site-specific management, the stability of the ffb yields should be considered also to avoid pitfalls in the interpretation of the yield maps.

The temporal stability maps for both treatments produced by point kriging are presented in Fig. 3. These maps show the ffb yield fluctuations of oil palms with time irrespective of their productivity. Without $\mathrm{N}$ fertilizer application, there was a gradual change in the stability of ffb yields from the western to the eastern part of the field. The western portion of the field had unstable ffb yields compared with the eastern portion, suggesting that the interpretation of the yield map there

\section{a. With $\mathrm{N}$}
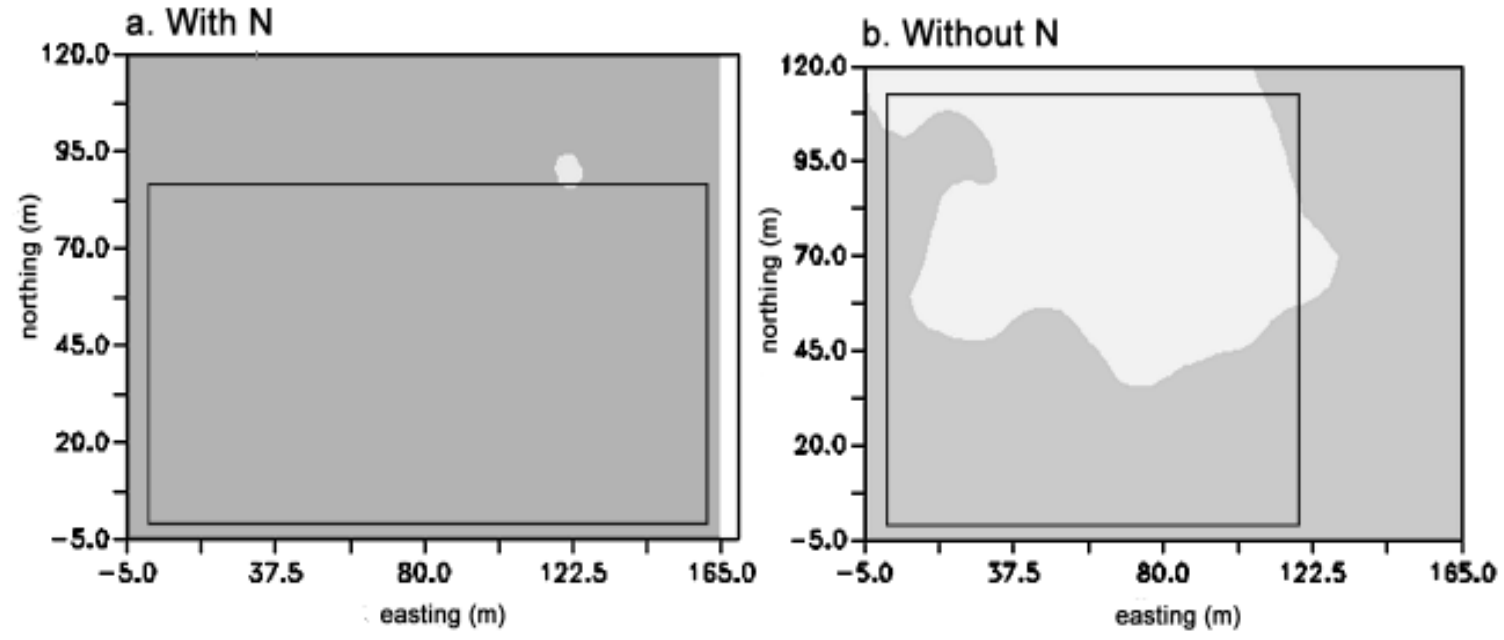

would have high uncertainty. Part of this uncertainty could be overcome with $\mathrm{N}$ manuring as discussed earlier. Figure 3 also shows that a portion of the $\mathrm{N}$ treated palms in the north had stable ffb yields while the

Table 3: Distribution of palms (\%) in different categories of mean yield and temporal yield stability as influenced by $\mathrm{N}$ treatment

\begin{tabular}{|c|c|c|c|c|c|}
\hline \multirow[b]{2}{*}{ Treatment } & \multirow[b]{2}{*}{$\begin{array}{l}\text { FFB yields } \\
\left(\mathrm{t} \mathrm{ha}^{-1} \text { year }^{-1}\right)\end{array}$} & \multicolumn{3}{|c|}{ Coefficient of variation $(\%)$} & \multirow[b]{2}{*}{ Total } \\
\hline & & $\leq 35^{\mathrm{d}}$ & $35<\mathrm{CV}<45^{\mathrm{e}}$ & $\geq 45^{f}$ & \\
\hline \multirow[t]{4}{*}{ With N } & $\geq 30^{\mathrm{a}}$ & 21.8 & 74.1 & 3.5 & 99.4 \\
\hline & $20<$ yields $<30^{b}$ & 0.6 & & & \\
\hline & $\mathrm{Y} \leq 20^{\mathrm{c}}$ & & & & 0.6 \\
\hline & Total & 22.4 & 74.1 & 3.5 & \\
\hline \multirow[t]{4}{*}{ Without N } & $\geq 30^{\mathrm{a}}$ & & 16.0 & 5.9 & 21.9 \\
\hline & $20<$ yields $<30^{b}$ & & 24.3 & 30.2 & 54.4 \\
\hline & $\mathrm{Y} \leq 20^{\mathrm{c}}$ & & 10.1 & 13.6 & 23.7 \\
\hline & Total & & 50.3 & 49.7 & 100.0 \\
\hline
\end{tabular}

Note: $\mathrm{a}, \mathrm{b}$ and $\mathrm{c}$ denote high, moderate and low $\mathrm{ffb}$ yields respectively $\mathrm{d}$, e and $\mathrm{f}$ denote stable, fairly stable and unstable ffb yields respectively

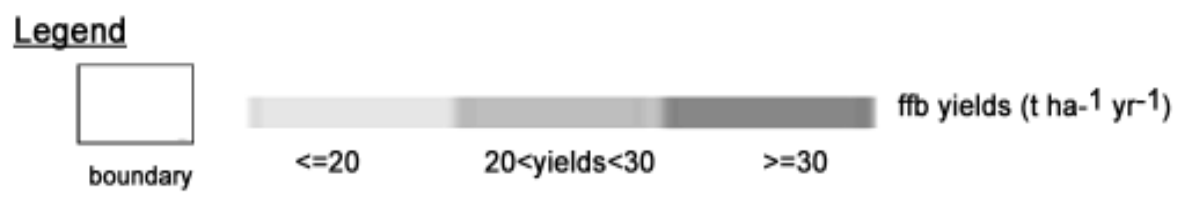

Fig.2: Distribution of oil palm yield for with and without $\mathrm{N}$ application 

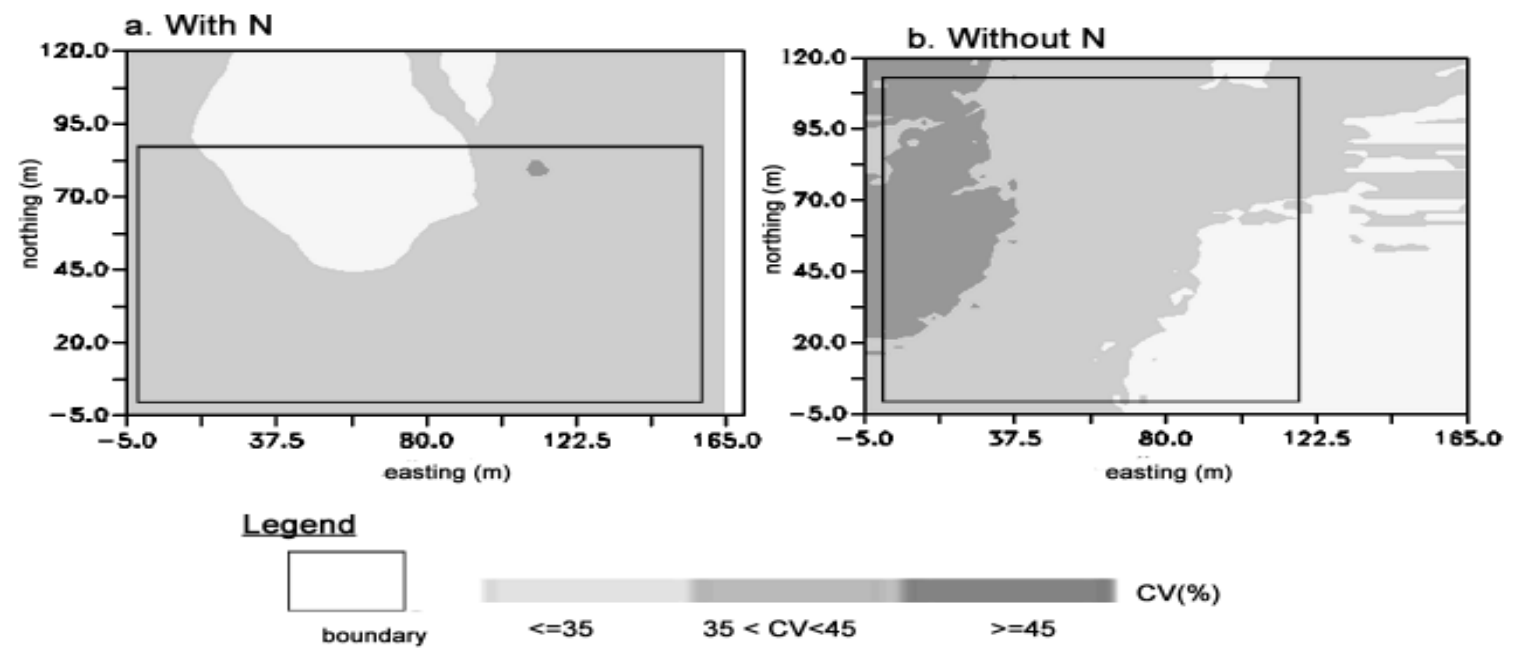

Fig. 3: Temporal stability map for with and without $\mathrm{N}$ applications
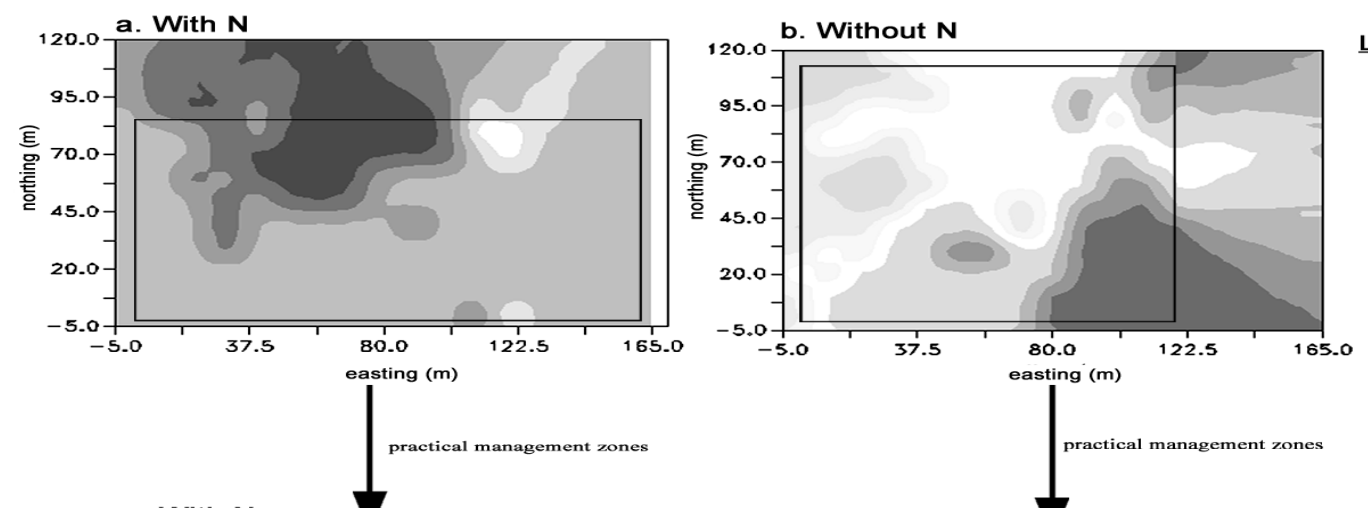

Legend
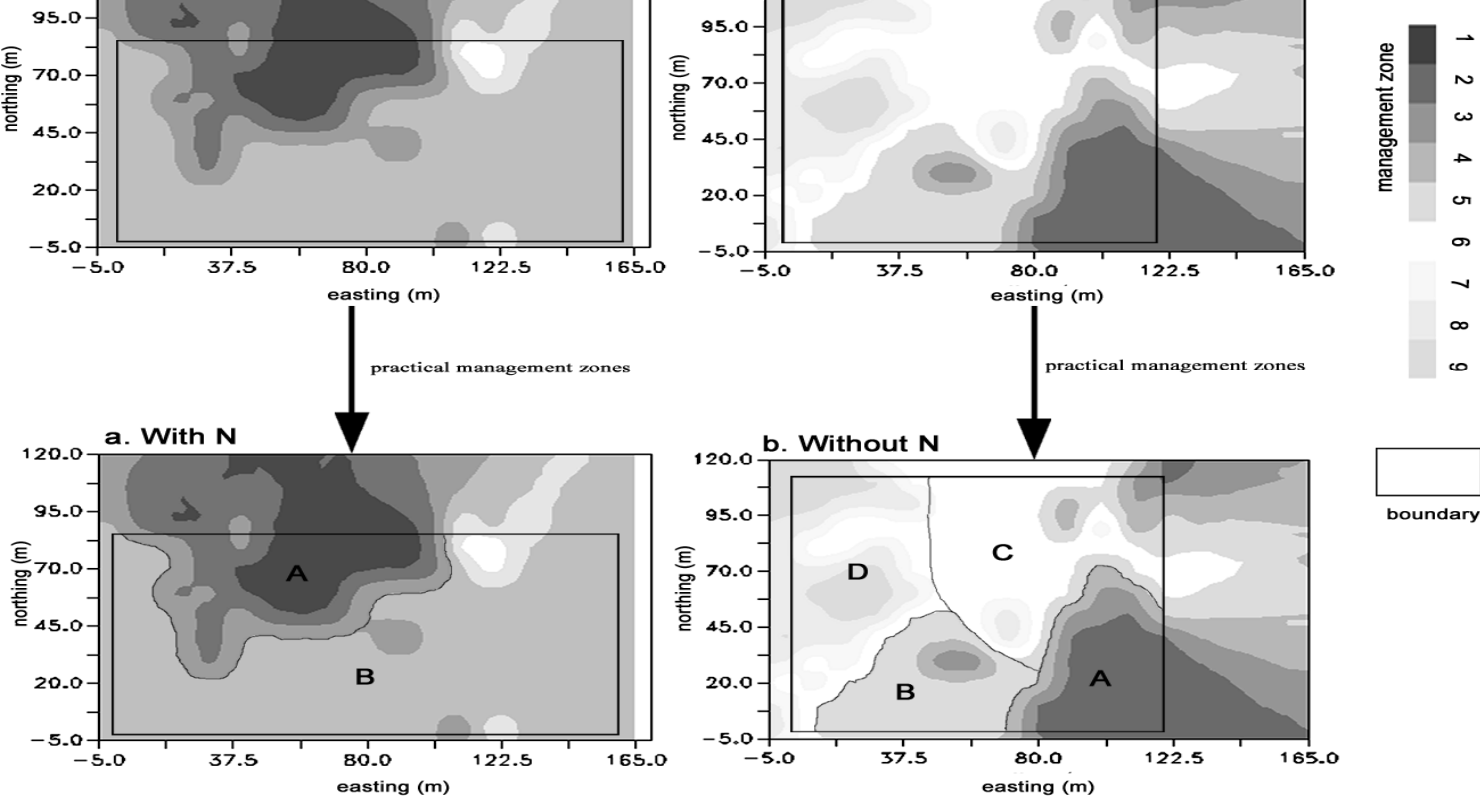

Fig. 4: Management zone maps for with and without $\mathrm{N}$ applications

balance showed fair temporal stability. This implies that fertilizer application, which is an exogenous factor, could not overcome the temporal yield fluctuations of oil palms.

Classified Management Zone Maps: The 3 classes each of ffb yield and temporal stability were combined to produce 9 management zones (Table 4). Zone 1 represents the highly desirable oil palms of high, stable yields while the worst scenario is Zone 9 with low, unstable $\mathrm{ffb}$ yields. Therefore, the management zones combined the important spatial and temporal features in the $\mathrm{ffb}$ yield variation for decision making. Based on this information, the management zone maps for both treatments were produced using point kriging (Fig. 4).

In the area with $\mathrm{N}$ fertilizer, a zone of high, stable yields was found in the northern portion with lower ffb yields as it radiated southward. It then changed to Zone 
Am. J. Applied Sci., 5 (10): 1376-1383, 2008

Table 4: Management classes based on the combined information of mean yield and temporal yield stability classes

\begin{tabular}{llll}
\hline $\begin{array}{l}\text { Management } \\
\text { class }\end{array}$ & $\begin{array}{l}\mathrm{ffb} \text { yields } \\
\left(\mathrm{t} \mathrm{ha}^{-1} \mathrm{yr}^{-1}\right)\end{array}$ & $\mathrm{CV}(\%)$ & Remark \\
\hline 1 & $\mathrm{y} \geq 30$ & $\mathrm{CV} \leq 35$ & High, stable yield \\
2 & $20<\mathrm{y}<30$ & $\mathrm{CV} \leq 35$ & Moderate, stable yield \\
3 & $\mathrm{y} \leq 20$ & $\mathrm{CV} \leq 35$ & Low, stable yield \\
4 & $\mathrm{y} \geq 30$ & $35<\mathrm{CV}<45$ & High, fairly stable yield \\
5 & $20<\mathrm{y}<30$ & $35<\mathrm{CV}<45$ & Moderate, fairly stable yield \\
6 & $\mathrm{y} \leq 20$ & $35<\mathrm{CV}<45$ & Low, fairly stable yield \\
7 & $\mathrm{y} \geq 30$ & $\mathrm{CV} \geq 45$ & High, unstable yield \\
8 & $20<\mathrm{y}<30$ & $\mathrm{CV} \geq 45$ & Moderate, unstable yield \\
9 & $\mathrm{y} \leq 20$ & $\mathrm{CV} \geq 45$ & Low, unstable yield \\
\hline
\end{tabular}

4 with high, fairly stable yields. In unfertilized area, there were more management zones with a moderate, stable yield zone in the eastern corner. As it moved towards the northwestern direction, pockets of low, unstable yields were found.

For practical management purposes, it is probably difficult to provide site-specific inputs to the scattered, small areas or strips of different management zones particularly in the unfertilized field (Fig. 4). However, there is a possibility to re-group some of the management zones depending on the management resources $^{[33]}$ (33). For example, the fertilized area could be simply divided into 2 management zones of high, stable yields and high, fairly stable yields (Fig. 4). Similarly, the unfertilized area could be demarcated into 4 management zones of moderate, stable yields (Zone A), moderate, fairly stable yields (Zone B), moderate, unstable yields (Zone $\mathrm{C}$ ) and low, unstable yields (Zone D). Different strategies could then be formulated to best manage the oil palms in each zone.

\section{CONCLUSIONS}

The spatial variations of $\mathrm{ffb}$ yields between and within plots were different and could be distinguished from semivariogram analysis. The semivariance was lower within plot and the lag distance (range) reached between 2 and 3-palm distance. With a triangular spacing in oil palm planting pattern, the optimum management zone for oil palm plantations was 37 palms. The large variation in $\mathrm{ffb}$ yields between the plots resulted in a sine wave model. Its maximum spatial range was about 6-palm distance which corresponded well to the experimental plot size of 30 (6×5) palms. Removal of $\mathrm{N}$ fertilizer resulted in a significant drop in ffb yields after 1992. High ffb yields above $30 \mathrm{t} \mathrm{ha}^{-1}$ year $^{-1}$ with better temporal stability could be obtained with $\mathrm{N}$ applications to the palms. Long-term monitoring of $\mathrm{ffb}$ yields is needed to characterize their spatial and temporal pattern for the development of management zones for practical site- specific inputs. However, further work is required to ascertain the optimum spatial and temporal scales of ffb yields for reliable interpretation of yield maps.

\section{REFERENCES}

1. Tarmizi, A.M., M.D. Tayeb and Z.Z. Zin, 1992. Maximum yield of oil palm in Peninsular Malaysia: Yield response and efficiency of nutrient recovery. In: Proceedings of 1990 ISOPB Workshop on Yield Potential in the Oil Palm. Thailand. pp: 145-153. International Society of Oil Palm Breeders and Palm Oil Research Inst. of Malaysia, Kuala Lumpur.

2. Goh, K.H., P.S. Chew and K.K. Kee, 1994. Maximising and maintaining oil palm yields on commercial scale in Malaysia. In: International Conference on Management for Enhanced Profitability in Plantations (ed K.H. Chee) pp: 121-141. International Society of Planters, Kuala Lumpur.

3. Corley, R.H.V., 1985. Yield potential of plantation crops. In: Proceedings of $19^{\text {th }}$ Colloquium, Potassium in the Agricultural Systems of the Humid Tropics. pp: 61-80. International Potash Institute, Bangkok, Thailand.

4. Tinker, P.B. 2000. The future research requirements for the oil palm plantation. In: International Planters Conference on Plantation Tree Crops in the New Millennium: The Way Ahead (ed E. Puspharajah) pp: 3-40. International Society of Planters, Kuala Lumpur.

5. Webster, C.C. 1938. A note on a uniformity trial with oil palms. Tropical. Agriculture. 16(1): 15-19.

6. Chapas, L.C. 1961. Plot size and reduction of variability in oil palm experiment. Emp. Journal of Experimental Agriculture, 29: 212-224.

7. Soh, A.C., C.H. Lee, Y.Y. Yong, C.W. Chin, Y.P. Tan, N. Rajanaidu and P.K. Phuah, 1989. The Precision of Oil Palm Breeding Experiments in Malaysia. In: Applications of Statistics to Perennial Tree Crops (A.C. Soh, N. Rajanaidu and M.H.B. Nasir) pp: 41-50. Palm Oil Research Institute of Malaysia, Kuala Lumpur

8. Goh, K.H. and A. Alwi, 1988. Uniformity trials with oil palms in Malaysia. In: Proceedings of 1987 International Oil Palm/Palm Oil Conference: Progress and Prospects (eds A.H. Halim, P.S. Chew, B.J. Wood and E. Puspharajah) pp: 677684. Palm Oil Research Institute of Malaysia and International Society of Planters, Kuala Lumpur. 
9. Goh, K.J., Tee, B.H., A.R. Anuar and C.Y. Woo, 2000. Spatial yield variation of oil palm in a fertiliser response trial in Malaysia. Proceedings. of the Soil Science Conference of Malaysia 2000. Malaysian Society of Soil Science, Kuala Lumpur.

10. McBratney, A.B., B.M. Whelan, J.A. Taylor and M.J. Pringle, 2000. A management opportunity index for precision agriculture. In: Proceedings of the 5th International Conference on Precision Agriculture and other Resource Management (P.C. Robert, R.H. Rust and W.E.Larson) pp. 16-19. Radisson Hotel South, Bloomington, Minnesota.

11. Blackmore, B.S. 1994. Precision farming: An introduction. Outlook in Agric. 23(4): 275-280.

12. Jaynes, D.B. and T.S. Colvin, 1997. Spatiotemporal variability of corn and soybean yield. Agron. J. 89: 30-37.

13. Larscheid, G., B.S. Blackmore and M. Moore, 1997. Management decisions based on yield maps. In: Precision Agriculture 97, Technology, IT and Management (ed J.V. Stafford) 2: 895-903 BIOS Scientific Publishers, United Kingdom.

14. Goh, K.J., B.H. Tee and A.R. Anuar, 2000. Applicability of precision farming for oil palm plantations in Malaysia. In: Seminar on Precision Farming. Universiti Putra Malaysia and Agricultural Inst. of Malaysia, Serdang, Malaysia.

15. Makridakis, S., S.C Wheelwright and R.J. Hyndman, 1998. Forecasting: Methods and Applications. 3rd ed. John Wiley and Sons, Inc., New York. pp: 641

16. SAS Inst. 1989. SAS/STAT guide for personal computers. Version $6,4^{\text {th }}$ ed. SAS Inst. Inc. Cary, NC. pp: 846

17. Journel, A..G. and N.J. Huijbergts, 1978. Mining geostatistics. Academic Press. New York, 600 pp.

18. Burgess, T.M. and R. Webster, 1980. Optimal interpolation and isarithmic mapping of soil properties. I. The semi-variogram and punctual kriging. Journal of Soil Science, 31: 315-331.

19. Webster, R. and A.B. McBratney, 1989. On the akaike information criterion for choosing models for variograms of soil properties. Journal of Soil Science, 40: 493-496.

20. Blackmore, B.S. 2000. The interpretation of trends from multiple yield maps. Computers and Electronics in Agriculture 26(200): 37-51.

21. Lim, K.C., C.B. Yee, K.H Goh and K.W. Chan, 1982. Results of a field experiment comparing various nitrogen fertilisers for oil palm. In: International Conference on Soils and Nutrition of Perennial Crops (eds A.T. Bachik, A.T. and E. Puspharajah, E.) pp: 393-410. Malaysian Society of Soil Science, Kuala Lumpur.
22. Tayeb, M.D., H.L. Foster, A.M. Tarmizi, A.B. Hamdan, H. Khalid and Z.Z. Zin, 1990. Sustaining oil palm FFB yield through optimum fertiliser management. In: Proceedings of 1989 PORIM International Palm Oil Development Conference. pp. 406-418. Palm Oil Research Institute of Malaysia, Kuala Lumpur.

23. Cressie, N.A.C., 1993. Statistics for spatial data (revised ed.). John Wiley and Sons, Inc. New York. pp: 900.

24. McBratney, A.B. and M.J. Pringle, 1997. Spatial variability in soil- implications for precision agriculture. In: Precision Agriculture'97: Vol. 1: Spatial Variability in Soil and Crop. pp: 3-31 BIOS Scientific Publishers, United Kingdom.

25. Zaharah, A.R., H.A.H Sharifuddin, A.M. Sahali and M.S. Hussein, 1989. Fertilizer placement studies in mature oil palm using isotope technique. The Planter, 65: 384-388.

26. Hashim, M.A.T. 1999. Potassium requirements of mature oil palm on coastal soils. Ph.D. Thesis. Universiti Putra Malaysia, Serdang, Malaysia.

27. Schroth, G., M.R.L. Rodrigues and S.A.D. Angelo, 2000. Spatial patterns of nitrogen mineralization, fertilizer distribution and roots explain nitrate leaching from mature Amazonian oil palm plantation. Soil Use and Management, 16: 222-229.

28. Foster, H.L., Tarmizi, A.M., Tayeb, M.D., Chang, K.C., Zin, Z.Z. and Halim, A.H. 1986. Fertiliser recommendations for oil palm in Peninsular Malaysia. (First approximation). PORIM Technology, 13: 16.

29. Ahmad, A. and Chan, K.W. 1989. Experimental plot size and shape for oil palm experiments. In: Applications of Statistics to Perennial Tree Crops (eds A.C. Soh, N. Rajanaidu and M.H.B. Nasir) pp: 57-16. Palm Oil Research Institute of Malaysia, Kuala Lumpur.

30. Emmott, A., J. Hall and R. Matthews, 1997. The potential for precision farming in plantation agriculture. In: Precision Agriculture '97, Vol. 1: Spatial Variability in Soil and Crop. pp: 289-296. BIOS Scientific Publishers, United Kingdom.

31. Corley, R.H.V. 1977. Oil palm yield components and yield cycles. In: International Developments in Oil Palm (eds D.A. Earp and W. Newall.) pp: 1-15. International Society of Planters, Kuala Lumpur.

32. Goh, K.J. and P.S. Chew, 2000. Agronomic requirements of oil palm for high yields in Malaysia. In: Proc. of the Seminar on Managing Oil Palm for High Yields: Agronomic Principles. pp: 98-135. Malaysian Society of Soil Sc. and Param Agricultural Soil Surveys, Kuala Lumpur.

33. McBratney, A.B. and Taylor, J.A. 2000. PV or not PV? In: Proceedings. of the $5^{\text {th }}$ Int. Symposium on Cool Climate Viticulture and Oenology- a Workshop on Precision Management. pp: 10 Melbourne, Australia. 